\title{
Interassociation consensus statement on cardiovascular care of college student-athletes
}

\author{
Brian Hainline, ${ }^{1}$ Jonathan Drezner, ${ }^{2}$ Aaron Baggish, ${ }^{3}$ Kimberly G Harmon, ${ }^{2}$ \\ Michael S Emery, ${ }^{4}$ Robert J Myerburg, ${ }^{5}$ Eduardo Sanchez, ${ }^{6}$ Silvana Molossi, ${ }^{7}$ \\ John T Parsons, ${ }^{1}$ Paul D Thompson ${ }^{8}$
}

- Additional material is published online only. To view please visit the journal online (http://dx.doi.org/10.1136/ bjsports-2016-096323).

${ }^{1}$ Sport Science Institute, National Collegiate Athletic Association, Indianapolis, Indiana, USA

${ }^{2}$ Department of Family Medicine, University of Washington, Seattle,

Washington, USA

${ }^{3}$ Cardiovascular Performance

Program, Massachusetts General Hospital, Boston, Massachusetts, USA

${ }^{4}$ Krannert Institute of

Cardiology, Indiana University

School of Medicine,

Indianapolis, Indiana, USA

${ }^{5}$ Division of Cardiology, University of Miami Miller

School of Medicine, Miami, Florida, USA

${ }^{6}$ American Heart Association, Dallas, Texas, USA

${ }^{7}$ Division of Pediatric

Cardiology, Department of

Pediatrics, Baylor College of

Medicine, Houston, Texas, USA

${ }^{8}$ Division of Cardiology,

Hartford Hospital, Hartford,

Connecticut, USA

\section{Correspondence to}

Dr Brian Hainline, Sport

Science Institute, National

Collegiate Athletic Association,

P.O. Box 6222, Indianapolis,

IN 46206-6222, USA:

bhainline@ncaa.org

This paper is co-published with the Journal of the American College of Cardiology

Accepted 5 May 2016 Published Online First 31 May 2016

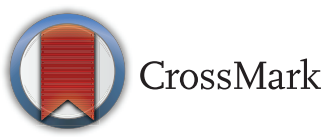

To cite: Hainline $B$, Drezner J, Baggish A, et al. Br J Sports Med

2017:51:74-85.

\section{ABSTRACT}

Cardiovascular evaluation and care of college studentathletes is gaining increasing attention from both the public and medical communities. Emerging strategies include screening of the general athlete population, recommendations of permissible levels of participation by athletes with identified cardiovascular conditions and preparation for responding to unanticipated cardiac events in athletic venues. The primary focus has been sudden cardiac death and the usefulness of screening with or without advanced cardiac screening. The National Collegiate Athletic Association convened a multidisciplinary task force to address cardiovascular concerns in collegiate student-athletes, and to develop consensus for an interassociation statement. This document summarises the task force deliberations and follow-up discussions, and includes available evidence on cardiovascular risk, preparticipation evaluation and the recognition of and response to cardiac arrest. Future recommendations for cardiac research initiatives, education and collaboration are also provided.

\section{EXECUTIVE SUMMARY: INTERASSOCIATION CONSENSUS STATEMENT ON CARDIOVASCULAR CARE OF COLLEGE STUDENT-ATHLETES}

\section{The preparticipation evaluation}

1. The purpose of the preparticipation evaluation is to identify conditions that may put the student-athlete at unreasonable risk of death or catastrophic injury, with the potential to modify and reduce risk through individualised management. In addition, the preparticipation evaluation provides the following opportunities:

A. to ensure that current health problems are managed appropriately;

B. to identify conditions that serve as barriers to performance;

C. to allow the student-athlete an opportunity to establish a relationship with the team physician, athletic trainer and other members of the medical team who may be involved in providing continuing medical care;

D. to assess for characteristics that may place the student-athlete at risk for future injury or disease;

E. to review medications and/or supplements, including addressing possible requests for therapeutic use exemption; and
F. to educate student-athletes regarding health risks, health-related behaviour, and pertinent issues regarding safe play in sport.

2. Although all models of cardiac screening require more research and education to improve and validate both performance and feasibility, the NCAA supports, in concept, preparticipation cardiovascular screening using a comprehensive personal and family history and physical examination, such as the American Heart Association (AHA) 14-point recommendations, and/or the Pre-Participation Physical Evaluation Monograph, Fourth Edition (PPE-4).

3. The preparticipation evaluation process should be formalised and in writing.

A. The member institution's preparticipation examination should be conducted on campus under the supervision of the institution's director of medical services, or, if an off-campus approach is used, evaluations should be reviewed in a process supervised by the institution's director of medical services. The director of medical services should identify one clinician provider at the medical doctor/doctor of osteopathic medicine level (most likely the head team physician) and one clinician provider at the athletic trainer level (most likely the head athletic trainer) who will be charged with the responsibility for ensuring that the preparticipation cardiac screening is conducted with the necessary components, as documented in the following text. Medical records of the examination should be kept in an accessible, secure file for at least the duration of the student-athlete's college career, and should accompany the athlete during any school transfers.

4. As afforded by local resources, cardiac screening on campus is encouraged in an effort to maintain a consistent and high-quality level of care.

A. For member institutions that choose to rely on external care providers to provide preparticipation evaluations, an on-campus mechanism should be established to confirm that the preparticipation evaluations are thoroughly reviewed. The goal of the review is to ensure follow-up and completion of any potential abnormal finding (either confirmed or dismissed) prior to organised athletic participation.

5. To ensure that team physicians are chosen and retained on the basis of broadly accepted 
criteria, member institutions that choose, appoint and oversee team physicians should be familiar with the Team Physician Consensus Statement: 2013 Update. $^{1}$

6. It is recognised that many member institutions use the ECG as part of preparticipation cardiac screening, even though there is no consensus as to the short-term and long-term risk/benefit ratio of such an approach. For those member schools that choose to use the ECG as part of the preparticipation cardiac screening, the following guidance is provided:

A. Pre-ECG screening planning and coordination:

- Before preparticipation physicals are conducted, team physicians, athletic trainers and athletic administrators should meet to discuss the execution of ECG screening in student-athletes. A cardiovascular specialist with the requisite expertise to provide athlete ECG over-reading services, and to coordinate any downstream testing dictated by ECG abnormalities should be identified.

- The implementation of ECG screening for all student-athletes versus targeted high-risk groups should be discussed and agreed on.

- Student-athletes should be provided information regarding the rationale for using ECG screening, and the possible risk versus benefit of adding ECG screening.

- The standards for ECG interpretation should be reviewed and agreed on, and avenues for prompt secondary cardiac testing of ECG abnormalities outlined.

B. Screening protocol:

- ECG screening should be implemented as part of an integrated cardiovascular screen using a standardised history and physical examination, such as the AHA 14-point recommendations or the PPE-4.

- The ECG should be obtained with equipment and by persons trained according to American College of Cardiology (ACC)/AHA/Heart Rhythm Society recommendations. $^{2}$

C. Interpretation and secondary testing:

- The ECG should be interpreted with modern standards that distinguish normal findings related to physiological cardiac remodelling in trained athletes from abnormalities suggestive of an underlying pathological cardiac condition.

- Consensus guidelines on ECG interpretation in athletes, and a free, online training course are available online at the $B M J$ Learning web site. ${ }^{3}$

- The institution should provide cardiology oversight and resources, either on-site or at a regional referral centre, to interpret suspicious ECGs and guide and perform secondary testing that may be required for athletes whose ECG results call for further clarification.

D. Management of identified cardiac conditions associated with sudden cardiac death (SCD):

- In keeping with the NCAA's requirement that each member institution is responsible for protecting the health of and providing a safe environment for each student-athlete, the management of identified cardiac disorders and all sport eligibility decisions are ultimately the responsibility of the institutional primary athletics healthcare providers in consultation with subspecialty consultants, including a primary cardiology point person.

- The ACC/AHA provides recommendations for safe participation in athletes with cardiovascular conditions that can be used as an initial guideline. A model that uses a comprehensive evaluation, extensive patient/ family counselling, and prudent medical management for risk reduction and informed decision-making that involves all key stakeholders in the oversight of the athlete (eg, coaches, athletic trainers, team physicians and athletic directors) provides a sensible strategy to structure difficult cardiac clearance decisions.

\section{Recognition and response to cardiac arrest, including emergency action plans}

1. Best practices strongly recommend a written emergency action plan (EAP) for the treatment of cardiac arrest. Online resources are available from the AHA. ${ }^{4}$ Essential aspects of the plan include:

A. Ensuring the training of anticipated responders in cardiopulmonary resuscitation (CPR) and use of an automated external defibrillator (AED). Such training should not be limited to athletic trainers and team physicians, but should rather be inclusive, including, but not limited to, strength and conditioning coaches, sport coaches, and administrative personnel with consideration in student-athletes, as resources allow.

B. Establishing an effective emergency communication system. The communication system should be in place before the beginning of the academic year.

C. Ensuring easy access to early defibrillation.

- Easy access means that there should be AEDs in the immediate vicinity (within a 3-min walk) of all high-risk locations, including, but not limited to: the weight room/strength and conditioning room, basketball court (s), football/soccer/lacrosse/baseball/softball fields, track and field space and indoor or other training facilities.

D. Ensuring properly charged and functioning AEDs. There should be a checklist maintained for each AED that indicates the date when the AED was checked and by whom. This should be an assigned function, and the check should occur at least monthly for both the battery charge and the electrode pads. A 'readiness' check by the athletic trainer or team physician before each practice or competition is encouraged. Manufacturer guidelines should be followed.

E. Integrating on-site responder and AED programmes with the local emergency medical services (EMS) system. Such integration should be developed before the beginning of the academic year, and should differentiate routine practice from competitions. For anticipated high-volume competitions (eg, football/basketball games), the point of entry/exit for emergency medical responders/vehicles should be clearly established beforehand.

F. Practicing and reviewing the emergency response plan at least annually.

\section{INTRODUCTION}

The National Collegiate Athletic Association (NCAA) convened a multidisciplinary task force at its headquarters in Indianapolis, Indiana, from 23 to 24 September 2014, to address cardiovascular care in the collegiate student-athlete (see online supplementary appendix for a list of participants). The purpose of the task force was to discuss and evaluate cardiovascular concerns in collegiate student-athletes, and to develop an interassociation consensus statement and recommendations for the future. The primary focus was sudden cardiac death (SCD), and the usefulness of screening with or without ECG (not including 
echocardiogram). Other more general cardiovascular issues were discussed in breakout groups. This document summarises the task force and follow-up discussions with task force members during the review process. The document addresses:

1. Cardiovascular risk in collegiate student-athletes

2. The preparticipation evaluation

3. Evidence evaluating the efficacy of preparticipation screening for detection of cardiovascular risk

4. ECG as a screening tool for SCD risk prediction

5. Regional referral centres for evaluation of athletes suspected or known to have a cardiovascular condition

6. Recognition and response to cardiac arrest

7. Cardiac research initiatives.

This document also includes an Executive Summary of recommendations and a checklist of best practices for NCAA member institutions (box 1).

\section{CARDIOVASCULAR RISK IN COLLEGIATE STUDENT-ATHLETES}

Whereas there is a general health benefit from regular exercise, ${ }^{5}$ sports participation presents additional risk for injuries. ${ }^{6}{ }^{7}$ Although sports activity during exertion, including both training and competition, has been reportedly associated with an increased risk for $\mathrm{SCD}^{8}{ }^{9}$ the issue remains incompletely resolved. ${ }^{10}$

For the purposes of this document, SCD is defined as an unexpected death due to cardiac causes that occurs in a short time period in a person with or without previously known cardiovascular disease. SCD should be differentiated from exertionrelated death in athletes that is not from a primary cardiac cause, for example, heat stroke and rhabdomyolysis. ${ }^{11}$ SCD in NCAA student-athletes is variously cited as either an uncommon event ${ }^{12-14}$ or as an event that occurs with such regularity that it demands further scrutiny. ${ }^{15-17}$ As with many epidemiological debates, the truth depends on how the question is framed, the methodological approach used, and the determination of whether SCD occurred during or soon after sport participation, or occurred as part of the larger population-risk of SCD. Estimates of SCD for US college athletes range from 1 in $43000(0.0023 \%)$ to 1 in $83000(0.0012 \%)$, and some athlete groups appear to be at a higher risk; ${ }^{12} 1517$ the SCD mortality rate is lower when postmortem data is used to establish cardiovascular diagnosis. ${ }^{10}$ The most common non-traumatic cause of death among college athletes is SCD,${ }^{17}$ and SCD represents

\section{Box 1 Cardiovascular care checklist of best practices for NCAA member institutions}

\section{Preparticipation evaluation of student-athletes}

- The purpose of the evaluation, as stated in the 2014-2015 NCAA Sports Medicine Handbook, ${ }^{19}$ is explained to the student-athlete.

- The cardiac evaluation includes, at minimum, a comprehensive personal and family history, and physical examination, such as the AHA 14-point evaluation or the Pre-Participation Physical Evaluation Monograph, Fourth Edition.

- The preparticipation evaluation is either conducted on campus under the supervision of the institution's director of medical services or is reviewed by a process that is supervised by the institution's director of medical services.

- If an ECG is included in addition to history and physical screening, best practices include:

$\square$ Pre-ECG screening planning is performed with a multidisciplinary team.

$\square$ The student athlete is provided an in-depth explanation for the rationale of ECG screening and the possible risk vs benefit of adding ECG screening.

$\square$ Modern athlete-specific ECG interpretation standards are used.

Skilled cardiology oversight is available.

Emergency action plan for cardiac arrest

- A written emergency action plan for treatment of cardiac arrest is in place and has been reviewed and rehearsed among the following key personnel:

$\square$ All primary athletic healthcare providers (athletic trainers and team physicians).

$\square$ Athletic director and director of medical services.

$\square$ All strength and conditioning coaches.

- The emergency action plan for cardiac arrest addresses each of the following:

$\square$ All athletic trainers, team physicians and strength and conditioning coaches have received training/certification in CPR and AED use.

$\square$ A communication system has been established that ensures a rapid and coordinated response to cardiac arrest, both internally and for emergency medical services (EMS).

$\square$ AEDs are placed strategically near all high-risk venues, including weight rooms, indoor arenas/courts, practice facilities, stadiums and fields where organised sports take place.

$\square$ Signage is clearly visible and strategically placed to indicate the location of each AED.

$\square$ AEDs are never behind locked doors, and are checked (with appropriate signoff) at least monthly for proper battery charge and functional electrode pads.

$\square$ EMS entry and exit are predetermined; and

This checklist can be used as a resource when evaluating institutional cardiac care plans. The checklist has been designed to help institutions become better informed and educated about the best practices that are endorsed in this interassociation document. Please note that the Interassociation Consensus Statement on Cardiovascular Care of College Student-Athletes does not provide prescriptive details regarding clinical care, as such care is individualised for the needs of each student-athlete and is on the basis of consensus and evidence-based care that is consistent with the standards of a team physician and cardiovascular consultant. AED, automated external defibrillator; CPR, cardiopulmonary resuscitation. 
$\sim 75 \%$ of fatalities in college student-athletes during sport and exercise. ${ }^{15}$ For over 30 years, 5-10 NCAA student-athletes have died per year of SCD; however, the number of athletes with cardiac arrest who survived is unknown. ${ }^{18}$

NCAA-focused research led to an analysis of SCD in NCAA athletes over a 10-year period (2003-2013). ${ }^{15} 17$ The analysis was conducted using cases identified in the NCAA Memorial Resolutions list, media reports and NCAA catastrophic insurance data. Autopsy reports were reviewed when possible, and only cases with confirmed cardiac aetiologies or circumstances consistent with SCD were included. The overall risk of SCD in an NCAA student-athlete during or soon after exertion is estimated at 1 in 54000 athletes/year $(0.0019 \%)$. The exertion-related risk of SCD in a male athlete is 1 in $38000(0.0026 \%)$, which is higher than the 1 in $122000(0.00082 \%)$ risk for a female athlete, although SCD in female athletes still accounts for 20\% of all cases. African-American athlete SCD risk is 1 in 22000 $(0.0045 \%)$, which is three times higher than the 1 in 68000 $(0.0015 \%)$ risk in a Caucasian athlete. ${ }^{17}$

Some athlete groups are at higher risk than others. A male basketball student-athlete has an exertion-related SCD risk of 1 in $9000(0.011 \%)$, which is higher than any other athlete group. ${ }^{17}$ The risk of SCD in Division I men's basketball, or in an African-American male basketball player from any division is as high as 1 in $5200(0.019 \%)$. Other athlete groups with higher than average risk include men's soccer (1 in 24000 or $0.0042 \%)$, football (1 in 36000 or $0.0028 \%$ ), and women's cross-country ( 1 in 47000 or $0.0021 \%) .{ }^{17}$ Men's basketball accounts for only $4 \%$ of male NCAA athletes, but nearly $20 \%$ of all SCD cases. Men's basketball and football together represent $23 \%$ of all male NCAA athletes, but these two sports alone account for $50 \%$ of all SCD cases. These values should be interpreted with some caution, given the low absolute number of annual SCD occurrences, which makes accurate assessment of the rate of SCD in subgroups subject to large yearly variations.

\section{THE PREPARTICIPATION EVALUATION}

The NCAA currently requires every student-athlete to undergo a preparticipation evaluation conducted by a licensed medical doctor, or doctor of osteopathic medicine prior to participation in an NCAA sport. The preparticipation evaluation is required on matriculation to an institution (administered within 6 months prior to the student-athlete's participation in any practice, competition or out-of-season conditioning activities for the applicable academic year) with an annually updated health history questionnaire and blood pressure measurement. The 2014-2015 NCAA Sports Medicine Handbook ${ }^{19}$ stipulates that the medical evaluation should include a comprehensive health history, an immunisation history, and a relevant physical examination, concentrating on the cardiac, neurological and musculoskeletal systems. The medical evaluation must also include confirmation of sickle cell trait status, a solubility test for sickle cell trait, or a release declining the test. In addition, the Inter Association Consensus: Diagnosis and Management of Sport-Related Concussion Guidelines, ${ }^{20}$ which was released in July 2014, recommends that all student-athletes undergo a one-time baseline concussion assessment inclusive of concussion history, symptom evaluation and cognitive and balance assessment. With regard to the preparticipation cardiac evaluation, the 2014-2015 NCAA Sports Medicine Handbook ${ }^{19}$ states that consideration should be given to implementing the recommendations from the AHA or the PPE-4. ${ }^{21} 22$
The NCAA currently does not define the purpose of the preparticipation evaluation. Furthermore, the NCAA does not currently require: (1) that the institution's team physician conduct the medical evaluation; (2) that the institution's team physician and/or director of medical services review preparticipation evaluations performed by outside physicians; or (3) that preparticipation evaluations fulfil established criteria.

Various medical societies and authorities have characterised the screening objective of the preparticipation evaluation as a means to identify or raise suspicion of cardiovascular abnormalities and diseases that are associated with unsafe sport participation in general or SCD in particular, ${ }^{10}{ }^{21-25}$ and as a way to enhance the safety of athletic participation. ${ }^{26} 27$ These screening objectives differ from general education and wellness goals. Specifically, all these screening objectives share a common element: the identification of potentially lifethreatening conditions for which participation in competitive sports would place the athlete at a level of increased risk that some might find unacceptable, given the potential consequences.

The AHA issued recommendations for the preparticipation screening of competitive athletes in $1996^{26}$ and in $2007 .^{28}$ These recommendations included a 12-point personal and family history and physical examination, and were promoted as a potentially effective strategy to raise the suspicion of cardiovascular disease in athletes. ${ }^{28}$ In 2014, the AHA published updated preparticipation recommendations regarding cardiovascular screening and extended the scope to include all generally healthy young people between the ages of 12 and 25 years. ${ }^{10}$ The 2014 recommendations did not recommend large-scale, general population and universal cardiovascular screening with history and physical examination, citing no evidence of benefit. However, if done in athletes or other relatively small cohorts of young healthy people $12-25$ years of age, the AHA recommendations affirmed the use of the previous screening guidelines and added two more questions that led to a 14-point history and physical evaluation to raise the suspicion of cardiovascular disease (table 1). Additionally, the AHA recommended standardisation of forms used to guide the examination for high school and college athletes.

The Pre-Participation Physical Evaluation Monograph was first published in 1992, and has undergone periodic revisions, with the latest (fourth) edition published in 2010. ${ }^{21}$ The Monograph is a joint project of six medical organisations representing a wide range of physicians who perform preparticipation evaluations, with the latest edition endorsed by the AHA. The monograph includes a recommended standardised history questionnaire; there are 12 personal and family history questions related to cardiovascular screening on the basis of the AHA guidelines. The history questions from the PPE-4 and the AHA 14-point recommendations use slightly different wording and syntax, and are compared in table 1.

Importantly, the preparticipation evaluation offers many opportunities beyond screening for the identification of serious cardiovascular conditions. As noted in the IOC Consensus Statement on Periodic Health Evaluation of Elite Athletes, ${ }^{24}$ the preparticipation/periodic health evaluation can also serve the following functions:

1. To ensure that current health problems are managed appropriately.

2. To identify conditions that are barriers to performance.

3. To allow the athlete an opportunity to establish a relationship with the health personnel who will be involved in providing continuing care. 
Table 1 The 14-element AHA recommendations for preparticipation cardiovascular screening of competitive athletes versus the PPE-4

AHA recommendations ${ }^{10 *}$

\section{Personal history}

1. Chest pain/discomfort/tightness/pressure related to exertion

2. Unexplained syncope/near syncopeł

3. Excessive and unexplained dyspnoea/fatigue or palpitations, associated with exercise

4. Prior recognition of a heart murmur

5. Elevated systemic blood pressure

6. Prior restriction from sports

7. Prior testing for heart disease, ordered by a physician

\section{Family History Heart}

8. Premature death (sudden and unexpected or otherwise) before 50 years of age attributable to heart disease in $\geq 1$ relative

9. Disability from heart disease in a close relative $<50$ years of age 10. Hypertrophic or dilated cardiomyopathy, long QT syndrome or other ion channelopathies, Marfan syndrome, or clinically significant arrhythmias;

specific knowledge of genetic cardiac condition in family member

Physical Examination

11. Heart murmur§

12. Femoral pulses to exclude coarctation

13. Physical stigmata of Marfan syndrome

14. Brachial artery blood pressure (sitting positional)ף
PPE-4 $4^{21}$

\section{Medical history}

\section{Heart Health Questions About You}

6. Have you ever had discomfort, pain, tightness or pressure in your chest during exercise?

5. Have you ever passed out or nearly passed out during or after exercise?

12. Do you get more tired or short of breath more quickly than your friends during exercise?

10. Do you get lightheaded or feel more short of breath than expected during exercise?

7. Does your heart ever race or skip beats (irregular beats) during exercise?

8. Has a doctor ever told you that you have any heart problems? If so, check all that apply:

$\square$ High blood pressure

$\square$ A heart murmur

$\square$ High cholesterol

$\square$ A heart infection

$\square$ Kawasaki disease

Other:-

1. Has a doctor ever denied or restricted your participation in sports for any reason?

9. Has a doctor ever ordered a test for your heart? (For example, ECG/EKG, echocardiogram)

11. Have you ever had an unexplained seizure?

\section{Health Questions About Your Family}

13. Has any family member or relative died of heart problems or had an unexpected death before age 50 years (including drowning, unexplained car accident or sudden infant death syndrome)?

14. Does anyone in your family have hypertrophic cardiomyopathy, Marfan syndrome, arrhythmogenic right ventricular cardiomyopathy, long QT syndrome, short QT syndrome, Brugada syndrome or catecholaminergic polymorphic ventricular tachycardia?

15. Does anyone in your family have a heart problem, pacemaker or implanted defibrillator?

16. Has anyone in your family had unexplained fainting, unexplained seizures, or near drowning?

\section{Physical Examination}

A. Heart

- Murmurs (auscultation standing, supine, \pm Valsalva)

- Location of point of maximal impulse

B. Pulses

- Simultaneous femoral and radial pulses

C. Appearance

- Marfan stigmata (kyphoscoliosis, high-arched palate, pectus excavatum, arachnodactyly, arm span >height, hyperlaxity, myopia, MVP, aortic insufficiency)

D. Blood pressure

Differences between AHA and PPE-4 recommendations are indicated in bold.

${ }^{*}$ Reprinted with permission from Maron et al. ${ }^{10}$

tParental verification is recommended for high school and middle school athletes.

łJudged not to be neurocardiogenic (vasovagal) in origin; of particular concern when occurring during or after physical exertion.

§Refers to heart murmurs judged likely to be organic and unlikely to be innocent; auscultation should be performed with the patient in both the supine and standing positions (or with

Valsalva manoeuvre), specifically to identify murmurs of dynamic left ventricular outflow tract obstruction.

१Preferably taken in both arms.

AHA, American Heart Association; ECG/EKG, electrocardiogram; MVP, mitral valve prosthesis; PPE, preperformance physical evaluation.

4. To look for characteristics that may put the elite athlete at risk for future injury or disease.

5. To review medications and/or supplements, including addressing possible therapeutic use exemption requests.

6. To educate athletes regarding health risks and health-related behaviour.

The preparticipation evaluation does not need to focus exclusively on current health and performance issues, but can also provide an opportunity to assess the risk for future health and quality-of-life matters. ${ }^{24}$ For example, hypertension stage
1 , or early metabolic syndrome, conditions that predispose to subsequent cardiovascular disease, ${ }^{29}{ }^{30}$ may be noted and addressed. Such anticipatory care can prevent future medical problems.

With regard to education, platforms can be developed that allow dissemination of information about key areas of student-athlete health, such as tobacco and recreational drug use, dietary patterns, performance-enhancing supplement use, concussion, weight management and mental health. ${ }^{31}$ Finally, the preparticipation evaluation offers an opportunity to 
encourage compliance among team physicians with consensus recommendations and legislation (eg, sickle cell trait). ${ }^{1}{ }^{32}$ To ensure that team physicians are chosen and retained on the basis of broadly accepted criteria, member institutions that choose, appoint and oversee team physicians should be familiar with the Team Physician Consensus Statement: 2013 Update. ${ }^{1}$

\section{EVIDENCE EVALUATING THE EFFICACY OF PREPARTICIPATION SCREENING FOR DETECTION OF CARDIOVASCULAR RISK}

Preparticipation screening has been conducted in the USA for more than 50 years. However, there is limited evidence supporting the effectiveness of preparticipation screening to achieve the generally agreed-on primary objective: the prevention of sports-related death in athletes. The history questions designed to detect previously undiagnosed cardiovascular conditions were developed through expert consensus and have never been validated scientifically. The generally broad and non-specific questions also elicit a high number of positive responses in athletes. In college athletes, at least one positive cardiovascular symptom, or family history response, was reported by $24-43 \%$ of athletes during preparticipation evaluations using either the AHA 12-point or PPE-4 questionnaires. $^{33} 34$ In high school athletes, initial positive history responses were reported by $68 \%$ of athletes undergoing a heart screen using the PPE-4 history questions. ${ }^{35}$ These responses have been considered 'false positive' responses by some investigators, ${ }^{34}$ but a positive response on a screening questionnaire must be differentiated from a true positive response on the basis of careful follow-up questions by the clinician. The AHA recommends review of positive questionnaire responses by physicians to determine if further evaluation is warranted; however, the ability of practitioners to discern true positive from false positive responses has also never been studied prospectively in a large-scale clinical trial.

Similarly, the addition of a resting 12-lead ECG to screening protocols has also never been shown, in an adequately designed study, to prevent SCD in athletes. Nevertheless, some authorities do recommend the use of a resting 12-lead ECG during the preparticipation cardiovascular screening of athletes. ${ }^{33} 3436$ Several studies have examined the ability of history, physical examination, and ECG to detect potentially life-threatening cardiovascular disease (which does not necessarily equate with identifying individuals who will actually experience a cardiac event). In general, the preparticipation history and physical examination have shown low sensitivity, high specificity, and a very low positive predictive value for identifying potentially lethal cardiac disorders (table 2). ${ }^{37}$ The majority of athletes (60-80\%) who experience SCD do not have recognised warning signs or symptoms prior to their event; therefore, this group will go undetected when screened by a protocol primarily reliant on questioning about prior symptoms. ${ }^{38} 39$ Since there is a high initial positive response rate to the recommended screening questions, and because symptoms leading up to SCD may be subtle or absent, it is critical that physicians conducting preparticipation examinations be well trained. Some data suggests that symptoms in patients with primary structural, functional or electrical cardiac abnormalities may, in fact, be misinterpreted or disregarded by medical staff. ${ }^{40}$

\section{ECG AS A SCREENING TOOL FOR SCD RISK PREDICTION}

The addition of a resting 12-lead ECG to a screening history and physical examination increases the sensitivity to identify many of the cardiac conditions associated with SCD, specifically cardiomyopathies, myocarditis, ion-channel disorders and ventricular pre-excitation. ${ }^{41}$ Nonetheless, two important causes of SCD in young athletes, anomalous aortic origin of a coronary artery and aortic root dilation, are not detected by ECG. ${ }^{26} 42$ Just as importantly, physician-to-physician variability in interpreting the ECG in elite athletes can be considerable. ${ }^{43} 44$ Although there is increasing momentum to standardise ECG interpretation in elite athletes, ${ }^{45} 46$ the acceptance of such standardisation, the dissemination of an agreed-on knowledge base for such standardisation, and the infrastructure to support such an approach are widely variable across the USA in general, and across NCAA member institutions in particular. This alone may have an effect on both the capacity and ability to implement any type of effective screening for SCD. Therefore, if ECG is included in the cardiovascular screening of athletes, it should be:

1. Disclosed that the ECG has limits for positive and negative predictive accuracy for SCD risk.

2. Interpreted with the current (and future evolving) state of knowledge that distinguishes physiological cardiac remodelling from findings suggestive of underlying cardiac pathology.

3. Conducted with adequate cardiology oversight and resources to assist with the secondary investigation of ECG abnormalities. The ECG should be obtained with equipment and by

Table 2 Sensitivity, specificity and positive predictive value of history, physical examination and ECG to detect potentially lethal cardiac disorders in athlete preparticipation screening

\begin{tabular}{|c|c|c|c|c|c|c|c|c|c|c|}
\hline \multirow[b]{2}{*}{ First author (Ref. \#) } & \multirow[b]{2}{*}{ Year } & \multicolumn{3}{|c|}{ Sensitivity } & \multicolumn{3}{|c|}{ Specificity } & \multicolumn{3}{|c|}{ Positive predictive value } \\
\hline & & History & PE & ECG & History & PE & ECG & History & PE & ECG \\
\hline Fuller ${ }^{70}$ & 1997 & 0 & 17 & 83 & 98 & 97 & 98 & 0 & 0.6 & 3.4 \\
\hline Wilson ${ }^{71}$ & 2008 & 0 & - & 100 & 98 & - & 99 & 0 & - & 22.5 \\
\hline Bessem $^{72}$ & 2009 & 25 & 0 & 75 & 95 & 97 & 93 & 4 & 0 & 9.0 \\
\hline Hevia $^{73}$ & 2009 & 0 & 0 & 100 & 99 & 100 & 94 & 0 & 0 & 2.7 \\
\hline Baggish $^{47}$ & 2010 & 0 & 33 & 66 & 96 & 98 & 84 & 0 & 0 & 2.4 \\
\hline Magalski $^{74}$ & 2011 & 44 & 11 & 100 & 75 & 95 & 91 & 0 & 1 & 9.5 \\
\hline Fudge $^{35}$ & 2014 & 40 & 0 & 100 & 69 & 90 & 95 & 0.5 & 8 & 6.9 \\
\hline Price $^{75}$ & 2014 & 20 & 40 & 100 & 88 & 96 & 97 & 0.4 & 3 & 8.1 \\
\hline Menafoglio $^{76}$ & 2014 & 0 & 0 & 100 & 99 & 99 & 96 & 0 & 0 & 9.5 \\
\hline
\end{tabular}


persons trained according to ACC/AHA/Heart Rhythm Society recommendations. ${ }^{2}$

4. Paralleled by the development of a registry for research into new knowledge regarding sensitivity and specificity of history, physical examination and ECG findings to the screening process.

Data suggests that screening by history and physical examination alone has a low sensitivity to detect conditions associated with SCD ${ }^{33}$ and that the addition of ECG, when properly interpreted and with skilled cardiology resources available, improves cardiovascular screening if the measurable endpoint is considered the detection of silent or congenital cardiac conditions associated with $\mathrm{SCD}^{46}$ (see box 2 for preliminary findings from an NCAA-funded research study addressing the feasibility of ECG screening). Although the AHA does not support a mandatory, nationalised ECG screening programme for athletes, it has long supported, in principle, ECG screening programmes that are well designed, prudently implemented and include adequate cardiology resources and expertise. ${ }^{102628}$ Even though the addition of an ECG may improve the sensitivity of detecting potentially fatal cardiovascular abnormalities, it may increase false-positive results, particularly if updated ECG screening criteria are not used. ${ }^{47}$ The false-positive rate can be reduced from $17 \%$ to $4.2 \%$ without affecting sensitivity when updated ECG screening criteria are used. ${ }^{47}$ Nevertheless, the observation that $0.25 \%$ of screened athletes have potentially dangerous cardiac conditions, ${ }^{49}$ and yet the number of deaths among NCAA athletes both in and out of competition has averaged 7.9 deaths/year over the past decade, ${ }^{17}$ suggests that ECG screening may detect cardiac conditions that would not lead to adverse events. The possibility that these individuals could receive apparently appropriate, but ultimately unnecessary interventions concerns some experts. There is an additional concern that ECGs routinely read in clinical practice, not by trained clinicians, are interpreted by ECG machine computer algorithms, which may increase the false positive rate. However, the longterm implications of whether early detection truly saves lives or, perhaps, causes harm through adverse medical events from secondary cardiac testing or procedures require additional study.

Furthermore, the potential gap between those member schools that offer ECG and/or echocardiogram screening and those that do not, represents not only a philosophical/medical variation, but also a potential difference in infrastructure support and available expertise. This presents a further limitation to understanding if broader ECG screening across NCAA member institutions will achieve the desired goal of preventing SCD in student-athletes. Clarification of these uncertainties, in light of the current data cited previously, would come from a 'big data' initiative that includes a large registry of ECG data and outcomes, such as recommended by the Institute of Medicine (IOM) for cardiac arrest generally, ${ }^{50}$ and new research funding strategies focused on such issues. ${ }^{51}$

\section{REGIONAL REFERRAL CENTRES FOR EVALUATION OF ATHLETES SUSPECTED OR KNOWN TO HAVE A CARDIOVASCULAR PROBLEM}

Cardiovascular issues associated with SCD can be addressed in a cardiovascular centre with or without a formal sports cardiology programme. Sports cardiology is a highly specialised segment of cardiovascular medicine that has achieved recognition by major cardiovascular organisations, such as the ACC. However, relatively few individual practitioners or institutions have embraced the knowledge base, practice skills and experience applicable to this discipline. This limitation is magnified for the circumstances of college athletics by the geographic and population dispersion of colleges and universities with athletic programmes. Certainly, most colleges and universities in major metropolitan areas, university-based medical centres, and many major community medical centres have access to the expertise needed to evaluate athletes who are determined by screening programmes to

Box 2 ECG screening in NCAA athletes: key preliminary findings from a 2-year multicentre feasibility trial

Abnormal ECGs were present in $192(3.7 \%)$ athletes.

A total of 1716 athletes (33\%) reported at least one positive response from the AHA symptom and family history questions, demonstrating the importance of clinician input in evaluating the questionnaire response.

Thirteen conditions $(0.23 \%$ of all athletes) associated with SCD or severe cardiac morbidity were identified, including:

- Wolff-Parkinson-White syndrome $(n=11)$

- Large atrial septal defect with right ventricle dilation requiring surgery $(n=1)$

- Hypertrophic cardiomyopathy $(n=1)$

All 13 had abnormal ECGs, and three had an abnormal history or physical examination.

The respective false-positive rates for detecting a potentially dangerous cardiac condition by ECG, physical examination and reported history responses were $3.4 \%, 2 \%$ and $33 \%$.

Of the abnormal ECGs, 1 in 16 (positive predictive value 6.3\%) represented a potentially serious cardiac condition, whereas one in 1000 (positive predictive value $0.1 \%$ ) positive history responses led to detection of a serious cardiac condition.

The average time loss from sport for athletes with an abnormal ECG was 2.6 days.

The average cost of follow-up testing for the 192 student-athletes with abnormal ECGs was not assessed.

No student-athlete had an adverse medical complication from additional cardiac testing, or was unnecessarily disqualified from sport.

From an NCAA-funded research study addressing the feasibility of ECG screening. ${ }^{49}$ The NCAA funded a 2-year, multicentre, prospective study on ECG screening in college student-athletes. Thirty-five NCAA institutions participated, and $>5200$ student-athletes underwent cardiovascular screening with ECG and the AHA-recommended history and physical examination. ECG were interpreted at a single institution by cardiologists with experience in ECG interpretation in athletes. The 'Seattle Criteria' for ECG interpretation were used by the cardiologists to determine abnormal findings (4S). The host institution's medical team determined evaluation of ECG abnormalities, management of detected cardiac conditions and all eligibility decisions.

AHA, American Heart Association; NCAA, National Collegiate Athletic Association; SCD, sudden cardiac death. 
require further evaluation, or who develop symptoms potentially due to cardiovascular problems during training or competition. Many of the smaller colleges and universities in low-density population areas do not have local access to such expertise. Accordingly, it is rational to consider developing regional referral centres to serve these functions. Their functions should include, but not be limited to:

1. Providing electronically accessible consultative resources for preparticipation ECG interpretation when local expertise for this specialised skill is not available.

2. Clarifying the cardiovascular status of athletes found to have a suspicious personal history, family history, physical examination, or ECG during routine preparticipation screening.

3. Evaluating new symptoms developing during training or competition, or in association with intercurrent illness, at any time.

4. Consulting regarding clearance to participate, or limitations on levels of intensity, for training and competition by athletes with identified inherited, developmental or acquired disorders, or to return to training or competition after resolution of an acquired cardiovascular problem, such as myocarditis.

Cardiovascular centres, as described, should be guided by specific standards for personnel, accessibility and resources. In addition, both cardiology centres and institutions/individuals with the knowledge base, practice skills and experience to evaluate and make recommendations for athletes with cardiac conditions should strive to follow consensus recommendations and guidelines principally addressing criteria for eligibility and disqualification from organised competitive sports for the purpose of ensuring the health and safety of athletes. ${ }^{23} 52-60$

\section{RECOGNITION OF, AND RESPONSE TO, CARDIAC ARREST}

Cardiac arrest is defined as a severe malfunction or cessation of the electrical and mechanical activity of the heart, and results in almost instantaneous loss of consciousness and collapse. ${ }^{50}$ Cardiac arrest in athletes can be effectively treated through prompt recognition, early cardiopulmonary resuscitation (CPR), and early use of an automated external defibrillator (AED). A written emergency action plan (EAP) for treatment of cardiac arrest that is well rehearsed will help to ensure an efficient and structured response to an athlete with a cardiac emergency who has collapsed, is not breathing normally or is only gasping (ie, agonal respirations), and who is unresponsive. Essential elements of such an EAP include: ${ }^{61} 62$

1. Training of anticipated responders in CPR and AED use (eg, other athletes, coaching staff, referees and so forth).

2. Establishing an effective emergency communication system.

3. Ensuring quick access to early defibrillation from collapse to first shock.

4. Ensuring that on-site AEDs are properly charged and functioning.

5. Integrating on-site responder and AED programmes with the local EMS system.

6. Practicing and reviewing the emergency response plan at least annually.

Prompt recognition of cardiac arrest is the first step to an efficient emergency response. ${ }^{5062}$ Although many cases of athlete collapse are transient and are from benign causes, cardiac arrest should be assumed in any student-athlete who has collapsed, is not breathing normally or only gasping and is unresponsive, and the EAP for cardiac arrest should be activated. Gasping and agonal respirations can occur in the first minutes after cardiac arrest and should not be interpreted as normal breathing. Brief seizure-like activity or involuntary arm and leg movements occur in $\sim 50 \%$ of individuals with cardiac arrest. ${ }^{63}{ }^{64}$ Therefore, cardiac arrest should not be mistaken for a seizure or syncope. In young athletes $(<35$ years of age), the most common causes of SCD are related to the following cardiovascular conditions: hypertrophic cardiomyopathy, congenital coronary anomalies, arrhythmogenic right ventricular cardiomyopathy, commotio cordis and ion channelopathies. ${ }^{65}$ Survival from cardiac arrest declines from $7 \%$ to $10 \%$ for every minute that defibrillation is delayed. ${ }^{66}$ Cardiac arrest in student-athletes is a more survivable event through prompt recognition and treatment with CPR and an AED, with survival rates as high as $89 \% .^{63} 67$

It is not sufficient to have in place a general protocol for treatment of cardiac arrest. Protocols must be situation-specific. ${ }^{61}$ For example, treatment of cardiac arrest in the basketball gymnasium during a routine practice will differ from treatment in the same gymnasium during a sold-out basketball game that results in traffic delays and access problems. Thus, coordination with emergency medical services (EMS) must be done beforehand, both to cover practice-related and game/championship events. Planning for emergency access by EMS must be an essential element of planning for all competition/championship events.

Whenever an athlete collapses and appears unresponsive, first responders should: ${ }^{68}$

1. Make sure the scene is safe.

2. Tap and shout at the unresponsive individual. If there is no breathing or only gasping, and if there is no definite pulse felt within $10 \mathrm{~s}$, then:

3. Call for help and activate the local EMS system (ie, call 911 or the local emergency services number). Access points for EMS to enter and exit the stadium, facility or other venue should be made clear to EMS and the facilities manager, and should be easily accessible for unimpeded entry and exit.

4. If an $\mathrm{AED}$ is known to be in the immediate vicinity, retrieve and apply the AED as soon as possible, and apply shock if there is a shockable rhythm. Then, follow the AED prompts regarding CPR and further shocks.

5. If an AED is not immediately available, begin chest compressions/CPR until an AED arrives.

The debate about the effectiveness of various screening examinations and tools to prevent SCD in student-athletes will undoubtedly continue. However, there is no debate that a wellrehearsed and effectively implemented EAP for treatment of cardiac arrest is effective at reducing the risk of death.

\section{CARDIAC RESEARCH INITIATIVES}

The NCAA is committed to expanding the understanding of SCD and advancing the cardiovascular care of athletes through education, research and creation of new resources. With the enactment of NCAA legislation that mandates catastrophic injury reporting, ${ }^{69}$ NCAA member institutions are required to report all catastrophic injuries occurring in student-athletes (including events that occur outside of athletic training and competition); sudden death and near-fatalities from cardiac arrest are counted as catastrophic injuries. Although SCD event reporting is mandatory for NCAA athletes, collecting information on sudden cardiac events for all college-aged and younger individuals would be informative for a greater understanding of incidence and prevention. Thus, future research on the incidence of life-threatening cardiovascular events in NCAA student-athletes will be directed by more precise data.

More accurate information is also needed on the specific aetiologies of SCD in college student-athletes. After the sudden 
death of any athlete, there is an opportunity to perform a comprehensive and expert forensic examination. This includes gross anatomical autopsy by a cardiovascular pathologist experienced in the distinction of athletic heart changes from structural pathologies associated with SCD. In the case of a negative or indeterminate autopsy, genetic testing can be conducted for known pathogenic gene mutations associated with ion-channel disorders, cardiomyopathies and other established causes of SCD in young persons. The NCAA has pledged to fund a study in which expert forensic examination and genetic testing will be available in cases of SCD. This means that postmortem tissue samples will be preserved to protect the quality of extracted DNA, and heart tissue will be preserved in accordance with methods that permit expert cardiac pathology examination that can identify specific cardiac conditions associated with SCD.

Additional research is needed to improve cardiovascular screening strategies. The standardisation of personal and family history questions requires additional study to determine both accuracy and efficacy. In addition, the feasibility, cost implications and downstream diagnostic testing yield of different screening strategies needs to be assessed, including those confined to history and physical examination versus those that also use testing, such as ECG and echocardiogram. Industry partnerships can be explored that may make more accurate and consistent ECG interpretation more widely available. Research can extend above and beyond preparticipation cardiovascular disease screening to include the effect of early life choices and habits on cardiovascular disease risk throughout the lifespan. Lifestyle issues related to tobacco, dietary patterns, physical activity and medical conditions (such as hypertension, dyslipidemia, metabolic syndrome and key cardiovascular adaptations to sport) are incompletely understood among NCAA student-athletes, both during college and later in life. Future research dedicated to understanding the scope and long-term clinical implications of these issues is important.

The NCAA is committed to partnering with national organisations dedicated to the continued education of primary care, sports medicine and cardiology physicians to enhance the cardiovascular care of athletes. Within this context, the NCAA has an important public health opportunity to better understand early markers of cardiovascular disease that may be present during college. It is entirely conceivable that precursors or early manifestations of cardiovascular disease in college student-athletes may lead to death on a substantially larger order of magnitude than SCD. The development of preventive care strategies and long-term surveillance will help to establish improved long-term cardiovascular health. In addition, the opportunity to use findings in college student-athletes for application to the 'college-aged' general population cohort cannot be understated.

Last, the IOM report, Strategies to Improve Cardiac Arrest Survival: A Time to Act, ${ }^{50}$ provides recommendations that can serve as collaborative opportunities for NCAA member institutions. Pertinent recommendations that are applicable across member schools include:

1. Establish a national cardiac arrest registry. The IOM recommends that the Centers for Disease Control and Prevention should expand and coordinate cardiac arrest data collection through a publicly reported and available national cardiac arrest registry. The National Center for Catastrophic Sport Injury Research can develop collaborative data collection strategies with the Centers for Disease Control and Prevention.

2. Foster a culture of action through public awareness and training. The IOM recommends partnerships that promote public awareness of the signs, symptoms and treatment of cardiac arrest, noting that such efforts require public CPR and AED training. This awareness and training creates a culture of action that prepares and motivates bystanders to respond immediately on witnessing a cardiac arrest. Member schools may be in a unique position to become a key component of such a culture of action. Every member school should have a cardiac emergency response plan and protocol. Online resources are available from the AHA. ${ }^{4}$

3. Adopt continuous quality improvement programmes. The IOM recommends an integrated healthcare adoption of

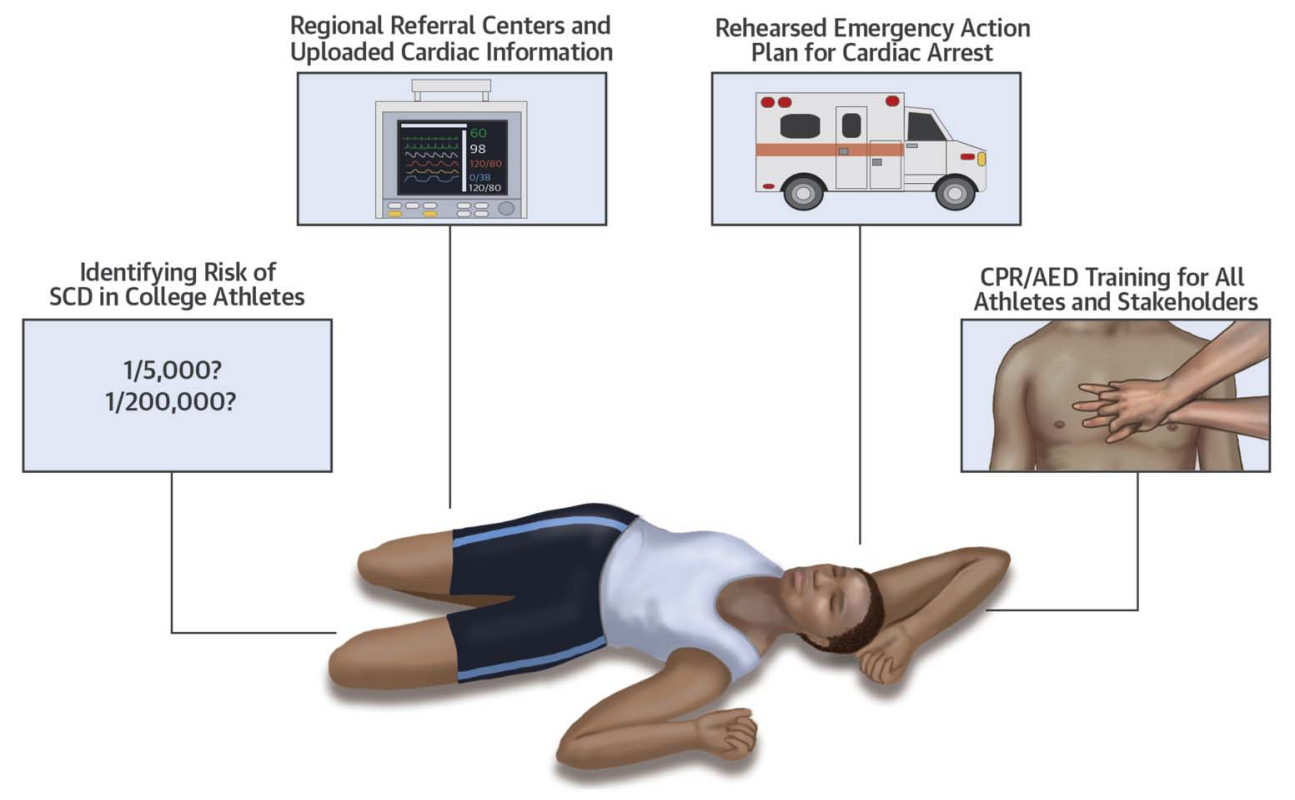

Figure 1 Central illustration. A summary of cardiovascular priorities in collegiate student-athletes. Cardiovascular priorities in college student-athletes range from more accurately defining the risk of SCD to developing and implementing referral centres and emergency action plans. $A E D$, automated external defibrillator; CPR, cardiopulmonary resuscitation; SCD, sudden cardiac death. 
continuous quality improvement programmes for cardiac arrest response. Member schools can become part of such programmes.

4. Accelerate research on pathophysiology, new therapies and translation of science for cardiac arrest. The IOM recommends a collaborative effort to build the nation's infrastructure that will support and accelerate innovative research on the causal mechanisms of onset, pathophysiology, treatment and outcomes of cardiac arrest. Coordinated data collection at NCAA member schools represents a unique opportunity to help advance such an effort.

5. Create a National Cardiac Arrest Collaborative. The IOM recommends the establishment of a National Cardiac Arrest Collaborative that will unify the cardiac arrest field, identify common goals, and build momentum within the field to ultimately improve survival from cardiac arrest with good neurological and functional outcomes. NCAA member schools are uniquely positioned to become part of this collaborative.

\section{CONCLUSIONS}

Cardiac arrest during training and sports participation is a leading cause of unexpected deaths and postarrest disabilities in NCAA athletes. The risk of SCD is higher in male and African-American athletes, and appears to be disproportionately high in men's basketball players. Cardiovascular screening in athletes should include a standardised personal and family history and a physical examination. ECG screening can increase the sensitivity to detect potentially lethal cardiac conditions if physician training is improved and cardiology expertise is available. If ECG screening is used, ECGs should be interpreted with modern standards that distinguish physiological changes from findings associated with pathological cardiac disorders. Secondary testing of screening abnormalities and management of identified cardiac disorders should be carried out in consultation with skilled cardiovascular specialists. All NCAA member institutions should have an established EAP to respond to an athlete with a cardiac emergency who has collapsed, is not breathing normally or only gasping, and is unresponsive, including the availability of AEDs at all sporting facilities. Although NCAA member institutions report all SCD events in student-athletes, collecting information on sudden cardiac events for all college-aged and younger individuals would be informative for greater understanding of incidence and prevention.

Together, NCAA member institutions have an opportunity to train coaching staff, referees and student-athletes to recognise and respond to a cardiac emergency on the field and in the community, and to become CPR ambassadors between the athletic programmes and the larger student population. Management of cardiac arrest with prompt recognition, early activation of the emergency response system, early CPR and early use of an AED provides the best chance of survival (figure 1).

Correction notice This paper has been amended since it was published Online First. A co-publication statement has been added on the first page.

Funding Funding for the multidisciplinary task force, held at the National Collegiate Athletic Association (NCAA) headquarters in September 2014, was provided by the NCAA Sport Science Institute. The task force included representatives from the following affiliations: American Academy of Pediatrics' Council on Sports Medicine and Physical Fitness; National Athletic Trainers' Association; College Athletic Trainers' Society; American Medical Society for Sports Medicine; American College of Cardiology Sports and Exercise Cardiology Leadership Council; National Federation of State High School Associations; American Orthopaedic Society for Sports Medicine; NCAA Student-Athlete Advisory Council; American Osteopathic Academy of Sports Medicine, National Strength and Conditioning Association; Collegiate Strength and Conditioning Coaches Association; American Heart Association; NCAA
Committee on Competitive Safeguards and Medical Aspects of Sports; and the American College of Sports Medicine. PDT has received research support from Genomas, Roche, Sanofi, Regeneron, Esperion, Amarin and Pfizer; has served as a consultant for Amgen, Regeneron, Merck, Esperion and Sanofi; has received speaker honoraria from Merck, AstraZeneca, Regeneron, Sanofi and Amgen; owns stock in AbbVie, Abbott Labs, CVS, General Electric, Johnson \& Johnson, Medtronic and JA Willey; and has provided expert legal testimony on exercise-related cardiac events and statin myopathy.

Disclaimer The views expressed in this paper by the American College of Cardiology's (ACC's) Sports and Exercise Cardiology Section Leadership Council do not necessarily reflect the views of the Journal of the American College of Cardiology or the ACC

Competing interests None declared.

Provenance and peer review Not commissioned; externally peer reviewed.

\section{REFERENCES}

1 Herring SA, Kibler WB, Putukian M. Team physician consensus statement: 2013 update. Med Sci Sports Exerc 2013;45:1618-22.

2 Kligfield P, Gettes LS, Bailey JJ, et al. Recommendations for the standardization and interpretation of the electrocardiogram; part I: the electrocardiogram and its technology. A scientific statement from the American Heart Association Electrocardiography and Arrhythmias Committee, Council on Clinical Cardiology; the American College of Cardiology Foundation; and the Heart Rhythm Society. J Am Coll Cardiol 2007:49: 1109-27.

3 Drezner J. ECG interpretation in athletes. BMJ Learning. http://learning.bmj.com/ learning/course-intro/.html?courseld=10042239 (accessed 24 Mar 2016).

4 American Heart Association. Cardiac EMERGENCY RESPONSE PLAN. http://cpr. heart.org/AHAECC/CPRAndECC/Programs/CPRInSchools/UCM_477994_ Cardiac-Emergency-Response-Plan.jsp (accessed 24 Mar 2016).

5 Paffenbarger RS Jr, Hyde RT, Wing AL, et al. A natural history of athleticism and cardiovascular health. JAMA 1984;252:491-5.

6 Sarna S, Sahi T, Koskenvuo M, et al. Increased life expectancy of world class male athletes. Med Sci Sports Exerc 1993;25:237-44.

7 Kujala UM, Sarna S, Kaprio J, et al. Hospital care in later life among former world-class Finnish athletes. JAMA 1996;276:216-20.

8 Corrado D, Basso C, Rizzoli G, et al. Does sports activity enhance the risk of sudden death in adolescents and young adults? J Am Coll Cardiol 2003;42:1959-63.

9 Toresdahl BG, Rao AL, Harmon KG, et al. Incidence of sudden cardiac arrest in high school student athletes on school campus. Heart Rhythm 2014;11:1190-4.

10 Maron BJ, Friedman RA, Kligfield P, et al. Assessment of the 12-lead electrocardiogram as a screening test for detection of cardiovascular disease in healthy general populations of young people (12-25 years of age): a scientific statement from the American Heart Association and the American College of Cardiology. J Am Coll Cardiol 2014;64:1479-514.

11 Yankelson L, Sadeh B, Gershovitz L, et al. Life-threatening events during endurance sports: is heat stroke more prevalent than arrhythmic death? J Am Coll Cardiol 2014;64:463-9

12 Maron BJ, Haas TS, Murphy CJ, et al. Incidence and causes of sudden death in U.S college athletes. J Am Coll Cardiol 2014;63:1636-43.

13 Maron BJ, Winkel B, Tfelt-Hansen J. Perspectives on cardiovascular screening. JAMA 2015;313:31-2

14 Maron BJ, Winkel B, Tfelt-Hansen J. Cardiovascular screening for young athletesreply. JAMA 2015;313:1674-5.

15 Harmon KG, Asif IM, Klossner D, et al. Incidence of sudden cardiac death in National Collegiate Athletic Association athletes. Circulation 2011;123:1594-600.

16 Harmon KG, Drezner JA. Cardiovascular screening for young athletes. JAMA 2015:313:1673-4.

17 Harmon KG, Asif IM, Maleszewski JJ, et al. Incidence, cause, and comparative frequency of sudden cardiac death in National Collegiate Athletic Association athletes: a decade in review. Circulation 2015;132:10-19.

18 Kucera K. Catastrophic sports injury surveillance for fatal cardiac events among collegiate athletes, 1982/93 to 2012/13: report prepared for NCAA Cardiac Summit, September 16, 2014. Chapel Hill, NC: National Center for Catastrophic Sport Injury Research, The University of North Carolina at Chapel Hill, 2014.

19 Parsons J, ed. 2014-15 NCAA sports medicine handbook. 25th edn. Indianapolis, IN: The National Collegiate Athletic Association, 2014.

20 Burnsed B. New guidelines aim to improve student-athlete safety. NCAA Media Center, 2014. http://www.ncaa.org/about/resources/media-center/news/ new-guidelines-aim-improve-student-athlete-safety (accessed 23 Mar 2016).

21 American Academy of Family Physicians, American Academy of Pediatrics, American College of Sports Medicine, American Medical Society for Sports Medicine. Preparticipation physical evaluation. 4th edn. Elk Grove Village, IL: American Academy of Pediatrics, 2010.

22 Maron BJ, Douglas PS, Graham TP, et al. Task force 1: preparticipation screening and diagnosis of cardiovascular disease in athletes. J Am Coll Cardiol 2005:45:1322-6. 
23 Maron BJ, Levine BD, Washington RL, et al. Eligibility and disqualification recommendations for competitive athletes with cardiovascular abnormalities: task force 2: preparticipation screening for cardiovascular disease in competitive athletes: a scientific statement from the American Heart Association and American College of Cardiology. J Am Coll Cardiol 2015;66:2356-61.

24 Ljungqvist $A$, Jenoure $P$, Engebretsen $L$, et al. The International Olympic Committee (IOC) consensus statement on periodic health evaluation of elite athletes March 2009. Br J Sports Med 2009:43:631-43.

25 Corrado D, Pelliccia A, Bjørnstad HH, et al. Cardiovascular pre-participation screening of young competitive athletes for prevention of sudden death: proposal for a common European protocol. Eur Heart J 2005;26:516-24.

26 Maron BJ, Thompson PD, Puffer JC, et al. Cardiovascular preparticipation screening of competitive athletes. A statement for health professionals from the Sudden Death Committee (clinical cardiology) and Congenital Cardiac Defects Committee (cardiovascular disease in the young), American Heart Association. Circulation 1996;94:850-6.

27 Maron BJ, Zipes DP, Kovacs RJ. Eligibility and disqualification recommendations for competitive athletes with cardiovascular abnormalities: preamble, principles, and general considerations: a scientific statement from the American Heart Association and American College of Cardiology. J Am Coll Cardiol 2015;66:2343-9.

28 Maron BJ, Thompson PD, Ackerman MJ, et al. Recommendations and considerations related to preparticipation screening for cardiovascular abnormalities in competitive athletes: 2007 update: a scientific statement from the American Heart Association Council on Nutrition, Physical Activity, and Metabolism: endorsed by the American College of Cardiology Foundation. Circulation 2007;115:1643-55.

29 Mancia G, Kjeldsen SE, Zappe DH, et al. Cardiovascular outcomes at different on-treatment blood pressures in the hypertensive patients of the VALUE trial. Eur Heart J 2016:37:955-64.

30 Eckel RH, Jakicic JM, Ard JD, et al. 2013 AHA/ ACC guideline on lifestyle management to reduce cardiovascular risk: a report of the American College of Cardiology/American Heart Association Task Force on Practice Guidelines. Circulation 2014;129:S76-99.

31 Estes NA III, Kovacs RJ, Baggish AL, et al. Eligibility and disqualification recommendations for competitive athletes with cardiovascular abnormalities: task force 11: drugs and performance-enhancing substances: a scientific statement from the American Heart Association and American College of Cardiology. J Am Coll Cardiol 2015:66:2429-33.

32 Maron BJ, Harris KM, Thompson PD, et al. Eligibility and disqualification recommendations for competitive athletes with cardiovascular abnormalities: task force 14: sickle cell trait: a scientific statement from the American Heart Association and American College of Cardiology. J Am Coll Cardiol 2015;66:2444-6.

33 Dunn TP, Pickham D, Aggarwal S, et al. Limitations of current AHA guidelines and proposal of new guidelines for the preparticipation examination of athletes. Clin J Sport Med 2015;25:472-7.

34 Drezner JA, Prutkin JM, Harmon KG, et al. Cardiovascular screening in college athletes. J Am Coll Cardiol 2015;65:2353-5.

35 Fudge J, Harmon KG, Owens DS, et al. Cardiovascular screening in adolescents and young adults: a prospective study comparing the Preparticipation Physical Evaluation Monograph 4th Edition and ECG. Br J Sports Med 2014;48:1172-8.

36 Dvorak J, Grimm K, Schmied C, et al. Development and implementation of a standardized precompetition medical assessment of international elite football players-2006 FIFA World Cup Germany. Clin J Sport Med 2009;19:316-21.

37 Harmon KG, Zigman M, Drezner JA. The effectiveness of screening history, physical exam, and ECG to detect potentially lethal cardiac disorders in athletes: a systematic review/metaanalysis. J Electrocardio/ 2015:48:329-38.

38 Maron BJ, Shirani J, Poliac LC, et al. Sudden death in young competitive athletes. Clinical, demographic, and pathological profiles. JAMA 1996;276:199-204.

39 Marcus Fl, McKenna WJ, Sherrill D, et al. Diagnosis of arrhythmogenic right ventricular cardiomyopathy/dysplasia: proposed modification of the Task Force Criteria. Eur Heart J 2010;31:806-14.

40 Campbell RM, Berger S, Drezner J. Sudden cardiac arrest in children and young athletes: the importance of a detailed personal and family history in the pre-participation evaluation. Br J Sports Med 2009;43:336-41

41 Drezner JA, Ackerman MJ, Cannon BC, et al. Abnormal electrocardiographic findings in athletes: recognising changes suggestive of primary electrical disease. Br J Sports Med 2013:47:153-67.

42 Basso C, Maron BJ, Corrado D, et al. Clinical profile of congenital coronary artery anomalies with origin from the wrong aortic sinus leading to sudden death in young competitive athletes. J Am Coll Cardiol 2000;35:1493-501.

43 Berte B, Duytschaever M, Elices J, et al. Variability in interpretation of the electrocardiogram in young athletes: an unrecognized obstacle for electrocardiogram-based screening protocols. Europace 2015;17:1435-40.

44 Sharma S, Dhutia H. Variation of electrocardiogram interpretation: yet another contributor to the Achilles heel of pre-participation electrocardiographic programmes in athletes. Europace 2015;17:1323-4.

45 Drezner JA, Ackerman MJ, Anderson J, et al. Electrocardiographic interpretation in athletes: the 'Seattle Criteria'. Br J Sports Med 2013:47:122-4.
46 Brosnan M, La Gerche A, Kalman J, et al. The Seattle Criteria increase the specificity of preparticipation ECG screening among elite athletes. $\mathrm{Br}$ J Sports Med 2014;48:1144-50.

47 Baggish AL, Hutter AM Jr, Wang F, et al. Cardiovascular screening in college athletes with and without electrocardiography: a cross-sectional study. Ann Intern Med 2010;152:269-75.

48 Wasfy MM, DeLuca J, Wang F, et al. ECG findings in competitive rowers: normative data and the prevalence of abnormalities using contemporary screening recommendations. Br J Sports Med 2015;49:200-6.

49 Drezner J. Electrocardiographic screening in NCAA athletes: a 2-year multicenter feasibility trial. Paper presented at: NCAA Cardiac Summit; 16 September 2014, Indianapolis, IN.

50 Graham R, McCoy MA, Schultz AM, eds., Committee on the Treatment of Cardiac Arrest: Current Status and Future Directions; Board on Health Sciences Policy; Institute of Medicine. Strategies to improve cardiac arrest survival: a time to act. Washington DC: The National Academies Press, 2015.

51 Myerburg RJ, Ullmann SG. Alternative research funding to improve clinical outcomes: model of prediction and prevention of sudden cardiac death. Circ Arrhythm Electrophysiol 2015;8:492-8.

52 Maron BJ, Udelson JE, Bonow RO, et al. Eligibility and disqualification recommendations for competitive athletes with cardiovascular abnormalities: task force 3: hypertrophic cardiomyopathy, arrhythmogenic right ventricular cardiomyopathy and other cardiomyopathies, and myocarditis: a scientific statement from the American Heart Association and American College of Cardiology. J Am Coll Cardiol 2015;66:2362-71.

53 Van Hare GF, Ackerman MJ, Evangelista JA, et al. Eligibility and disqualification recommendations for competitive athletes with cardiovascular abnormalities: task force 4: congenital heart disease: a scientific statement from the American Heart Association and American College of Cardiology. J Am Coll Cardiol 2015:66:2372-84.

54 Bonow RO, Nishimura RA, Thompson PD, et al. Eligibility and disqualification recommendations for competitive athletes with cardiovascular abnormalities: task force 5: valvular heart disease: a scientific statement from the American Heart Association and American College of Cardiology. J Am Coll Cardiol 2015:66:2385-92.

55 Black HR, Sica D, Ferdinand $K$, et al. Eligibility and disqualification recommendations for competitive athletes with cardiovascular abnormalities: task force 6: hypertension: a scientific statement from the American Heart Association and the American College of Cardiology. J Am Coll Cardiol 2015;66:2393-7.

56 Braverman AC, Harris KM, Kovacs RJ, et al. Eligibility and disqualification recommendations for competitive athletes with cardiovascular abnormalities: task force 7: aortic diseases, including marfan syndrome: a scientific statement from the American Heart Association and American College of Cardiology. J Am Coll Cardiol 2015;66:2398-405.

57 Thompson PD, Myerburg RJ, Levine BD, et al. Eligibility and disqualification recommendations for competitive athletes with cardiovascular abnormalities: task force 8: coronary artery disease: a scientific statement from the American Heart Association and American College of Cardiology. J Am Coll Cardiol 2015:66:2406-11

58 Zipes DP, Link MS, Ackerman MJ, et al. Eligibility and disqualification recommendations for competitive athletes with cardiovascular abnormalities: task force 9: arrhythmias and conduction defects: a scientific statement from the American Heart Association and American College of Cardiology. J Am Coll Cardiol 2015;66:2412-23.

59 Ackerman MJ, Zipes DP, Kovacs RJ, et al. Eligibility and disqualification recommendations for competitive athletes with cardiovascular abnormalities: task force 10: the cardiac channelopathies: a scientific statement from the American Heart Association and American College of Cardiology. J Am Coll Cardiol 2015:66:2424-8

60 Link MS, Estes NA III, Maron BJ. Eligibility and disqualification recommendations for competitive athletes with cardiovascular abnormalities: task force 13: commotio cordis: a scientific statement from the American Heart Association and American College of Cardiology. J Am Coll Cardiol 2015;66:2439-43.

61 Drezner JA, Courson RW, Roberts WO, et al. Inter-Association Task Force recommendations on emergency preparedness and management of sudden cardiac arrest in high school and college athletic programs: a consensus statement. J Ath Train 2007;42:143-58

62 Link MS, Myerburg RJ, Estes NA III. Eligibility and disqualification recommendations for competitive athletes with cardiovascular abnormalities: task force 12: emergency action plans, resuscitation, cardiopulmonary resuscitation, and automated external defibrillators: a scientific statement from the American Heart Association and American College of Cardiology. J Am Coll Cardiol 2015;66:2434-8.

63 Drezner JA, Rao AL, Heistand J, et al. Effectiveness of emergency response planning for sudden cardiac arrest in United States high schools with automated external defibrillators. Circulation 2009;120:518-25.

64 Drezner JA, Rogers KJ. Sudden cardiac arrest in intercollegiate athletes: detailed analysis and outcomes of resuscitation in nine cases. Heart Rhythm 2006:3:755-9. 
65 Vernuccio F, Grutta G, Fazio G. [Sudden cardiac death in athletes: is it always not preventable?]. Recenti Prog Med 2014;105:410-14.

66 Larsen MP, Eisenberg MS, Cummins RO, et al. Predicting survival from out-of-hospital cardiac arrest: a graphic model. Ann Emerg Med 1993;22: 1652-8.

67 Drezner JA, Toresdahl BG, Rao AL, et al. Outcomes from sudden cardiac arrest in US high schools: a 2-year prospective study from The National Registry for AED Use in Sports. Br J Sports Med 2013:47:1179-83.

68 Bhanji F, Donoghue AJ, Wolff MS, et al. Part 14: education: 2015 American Heart Association guidelines update for cardiopulmonary resuscitation and emergency cardiovascular care. Circulation 2015;132:S561-73.

69 The National Collegiate Athletic Association. Catastrophic injury reporting requirement starts Aug. 1. NCAA Media Center. 31 July 2014. http://www.ncaa. org/about/resources/media-center/news/catastrophic-injury-reportingrequirementstarts-aug-1 (accessed 23 Mar 2016).

70 Fuller CM, McNulty CM, Spring DA, et al. Prospective screening of 5,615 high school athletes for risk of sudden cardiac death. Med Sci Sports Exerc 1997;29:1131-8
71 Wilson MG, Basavarajaiah S, Whyte GP, et al. Efficacy of personal symptom and family history questionnaires when screening for inherited cardiac pathologies: the role of electrocardiography. Br I Sports Med 2008:42:207-11.

72 Bessem B, Groot FP, Nieuwland W. The Lausanne recommendations: a Dutch experience. Br J Sports Med 2009;43:708-15.

73 Hevia AC, Fernández MM, Palacio JMA, et al. ECG as a part of the preparticipation screening programme: an old and still present international dilemma. Br I Sports Med 2011:45:776-9.

74 Magalski A, McCoy M, Zabel M, et al. Cardiovascular screening with electrocardiography and echocardiography in collegiate athletes. Am J Med 2011;124:511-18.

75 Price DE, McWilliams A, Asif IM, et al. Electrocardiography-inclusive screening strategies for detection of cardiovascular abnormalities in high school athletes. Heart Rhythm 2014;11: 442-9.

76 Menafoglio A, Di Valentino M, Segatto JM, et al. Costs and yield of a 15-month preparticipation cardiovascular examination with ECG in 1070 young athletes in Switzerland: implications for routine ECG screening. Br I Sports Med 2014;48: $1157-61$ 